\title{
BASIC ANTHROPOMETRIC MEASUREMENTS AND PROFICIENCY IN THE GAME OF ADOLESCENT (UP TO 16-YEAR-OLD) MALE VOLLEYBALLERS AT ESTONIAN CHAMPIONSHIPS IN THREE DIFFERENT YEARS
}

\author{
Meelis Stamm $^{1}$, Raini Stamm ${ }^{2}$ \\ ${ }^{1}$ Faculty of Educational Sciences, Tallinn University, Tallinn, Estonia \\ ${ }^{2}$ Institute of Health Sciences and Sport, Tallinn University, Tallinn, Estonia
}

\begin{abstract}
The article analyses young male volleyballers' age, body build and performance at Estonian championships for up to 16-year-olds at three tournaments - Tartu 2005, Viljandi 2006 and Rakvere 2008. In all these years, the participants were the eight best teams of Estonia at the moment. A total of 197 boys were studied; 13 body measurements were taken. Proficiency in the game was assessed for both teams in parallel with two computers provided with the program Game.

Thirty-one indicators of proficiency in the game were calculated at each tournament. When we compared the tournament of 2005 with the tournament of 2008, we found statistically significant differences in nine indicators. The quality of the games has improved and the teams have become more equally matched. The number of spikes and blocks has increased; the indices of proficiency for all technical elements were higher in 2008 than in 2005. It is interesting that serve has changed from an element of putting the ball into the game into a genuinely attacking element. The number of ace serves has increased statistically significantly; the proficiency index of serves has rose by 2008. Unfortunately, however, the height and weight of the players decreased by 2008 . This is a cause for concern, as taller players are more successful in volleyball.
\end{abstract}

Keywords: volleyball, adolescent, anthropometry, game statistics, index of proficiency, performance 


\section{INTRODUCTION}

The article analyses the proficiency in the game at Estonian championships for male volleyballers aged up to 16 years and assesses their body build based on 13 basic measurements in 2005, 2006 and 2008. It is a cross-sectional study that shows how the quality of the game and the body build indicators in this age group have changed over four years.

\section{MATERIAL AND METHODS}

The sample consisted of 197 boys aged 13-15 years from 24 most successful volleyball teams of up to 16 year olds who participated in Estonian championships in Tartu in 2005, in Viljandi in 2005 and in Rakvere in 2008.

\section{Anthropometric variables}

During the intervals between the matches, all the 197 boys were measured anthropometrically using the method of Martin [4]. Thirteen body measurements were taken that in the present authors' earlier studies $[7,8]$ had shown significant correlation with proficiency in the game. These measurements were height, weight, suprasternal height, xiphoidal height, wrist breadth, chest circumference, waist circumference, hip circumference, upper thigh circumference, lower leg circumference, arm circumference, flexed and tensed arm circumference, and wrist circumference.

\section{Assessment of players' proficiency}

To record the games, an original computer program Game was used, which was first presented by R. Nõlvak (Stamm) in 1995. The methodology of the program has been introduced in a specialist journal in the USA [6].

The assessment of players' proficiency proceeded as follows: during the match, the expert registered, using the program Game, each case when a player performed a technical element (serve, reception, block, spike). This was done by pressing three keys on the keyboard: (1) which element was performed, (2) how it was performed (the grade for the performance on a five-point scale 1 excellent, 5 fault), (3) the number of the player who performed the element.

For all the elements, the program calculates each player's index of proficiency according to the following formula:

Index of proficiency $=\frac{\text { number of performances } \times \text { maximum grade }- \text { sum of grades }}{(\text { maximum grade }-1) \times \text { number of performances }}$ 
In addition to the index of proficiency, the program calculates the following data for each set and for the whole match: the number of all technical elements for each player and for the whole team, average indices of proficiency of each element for each player and for the whole team, points scored by performing the elements. A separate count was kept on the total number of successfully performed elements and their average number per game. The number of errors while performing each element and the average number of errors per game were also calculated. A total of 31 variables were calculated to evaluate the proficiency of the players.

The total number of games recorded in Tartu in 2005 was 28, in Viljandi in 2006 - 19, and in Rakvere in 2008 - 28.

\section{Statistical analysis}

The data were analysed using the SAS system. Means and standard deviations of anthropometric measurements for each tournament and separately for each age group (13-15) were calculated and the variables' correlations with age were found (Tables 1, 2, 3).

Using the data on elements performed by individual players, the statistical section of the program Game computed the players' and the whole team's essential technical data for a particular set and for the whole game - the total number of elements performed and the number of points gained.

Statistical analysis of the data was continued after the championships, using the SAS system, in order to compare the technical data of different tournaments. For this purpose, primary statistical analysis of each tournaments' technical data was performed where their mean and SD were computed, and the significance of the differences between the results of the first (2005) and the last (2008) tournaments were checked by the $\mathrm{t}$-test (Table 4 ).

\section{RESULTS}

We present the results of volleyballers' anthropometric measuring at three Estonian championships for boys aged up to 16 years (Tartu 2005, Viljandi 2006, Rakvere 2008). Tables 1, 2 and 3 present the values of 13 body measurements of players who participated in the championships separately according to age groups - the means and standard deviations of the boys aged 13,14 and 15 years. Table 1 describes the boys who participated in the tournament in Tartu in 2005, Table 2 - the boys who participated in the tournament in Viljandi in 2006 and Table 3 - in Rakvere in 2008. The players' mean height was the highest $(175.89 \mathrm{~cm}, \mathrm{SD}=8.4)$ in Viljandi in 2006 and the lowest $(173.25 \mathrm{~cm}, \mathrm{SD}=9.8)$ in 
Rakvere in 2008. The data of weight were similar, their mean being the smallest at the third tournament $(60.41 \mathrm{~kg}, \mathrm{SD}=9.9)$, while in the first two tournaments the boys' mean weight was respectively $62.2 \mathrm{~kg}(\mathrm{SD}=10.0)$ and $62.3 \mathrm{~kg}(\mathrm{SD}=9.8)$. From the viewpoint of proficiency in volleyball, we would have liked to see an increase in the players' mean height and weight by 2008 compared to 2005 and 2006. Then we would have been able to state that volleyball coaches apply the principle of talent scouting when composing training groups, as taller players are more successful in volleyball.

The last columns of Tables 1, 2, 3 show the relations of the players' anthropometric variables with age. Practically all the body measurements correlate with age; correlation strength $\mathrm{r}=0.2-0.6$. This is quite logical, as 13 -year-olds are somewhat shorter and lighter than 14- and 15-year-olds. Such a tendency is characteristic of all the three years of the study.

Table 4 presents the data on the boys' proficiency in the game at all the three tournaments according to 31 variables of proficiency. The mean results of proficiency in 2005 and 2008 have been compared statistically.

The comparison of the proficiency in the game at the tournaments of 2005 and 2008 reveals that the proficiency of performance of technical elements by players was higher in the last tournament (Rakvere 2008) compared to the first one (Tartu 2005).

The mean proficiency of serve in 2005 was $0.38(\mathrm{SD}=0.1)$ and in 20080.45 $(\mathrm{SD}=0.07)$. The mean proficiency of reception was 0.52 at the first tournament and 0.54 at the last one (SD 0.19 and 0.1 respectively); the mean proficiency of block 0.36 at the first tournament and 0.44 at the last one (SD 0.24 and 0.25 ) and the mean proficiency of spike 0.54 and 0.58 (SD 0.19 and 0.18 ). Still, a statistically significant difference in the proficiency indices of elements appeared only in the proficiency of serve (Table 4).

There were also other statistically significant differences in the elements of the game. As the Table shows, there are statistically significant differences in (1) total number of serves, (3) total number of ace serves, (4) mean number of ace serves, (10) mean number of reception errors, (13) total number of blocks, (17) total number of block errors and (18) mean number of block errors per game. In those cases, too, the results were higher at the third tournament in Rakvere.

Table 4 also enables us to see changes in the quality of games of up to 16-year-old male volleyballers. As the cohort who participated in the Estonian championships in 2005 is not the same as at the championships of 2008, we cannot assess the players' individual development. Nonetheless, we can see if the same age group three years later plays volleyball with the same proficiency or the performance of some elements has improved or deteriorated. We can 
compare whether the players make more or fewer of their own errors that result in the opponent gaining a point. The analysis of serve shows that, while in 2005 the serve was mainly an element used for putting the ball into the game, by 2008 it had become a genuine element of attack. The mean index of proficiency of serve has increased through the years from 0.38 to 0.41 and 0.45 ; the respective standard deviations being 0.1, 0.1 and 0.07 . While at the Estonian championships of 2005, 278 points were gained by ace serves (SD=4.26), in 2008 their number was 309 already $(\mathrm{SD}=4.18)$. The difference was statistically significant. Simultaneously, the number of errors at serve diminished - from 308 errors in $2005(\mathrm{SD}=4.3)$ to 204 errors in $2008(\mathrm{SD}=3.7)$.

Reception of serve has become weaker. This is shown by a statistically significant indicator - reception errors during the tournament. In 2005, the number of errors was $272(\mathrm{SD}=3.65)$, in $2008-292(\mathrm{SD}=4.2)$. The mean number of reception errors per person in a game has also increased statistically significantly - from $0.65(\mathrm{SD}=0.58)$ in 2005 to $0.75(\mathrm{SD}=0.62)$ in 2008 . It is very interesting that the mean index of proficiency for reception has nonetheless somewhat improved - from $0.52(\mathrm{SD}=0.19)$ in 2005 to $0.54(\mathrm{SD}=0.1)$ in 2008. The difference between the two tournaments, however, is not statistically significant. This contradiction can be explained by the fact that, although the number of reception errors increased, the number of successful receptions was also greater in 2008 than in 2005.

The total number of blocks was 938 in 2005 and 1057 in 2008. The difference between these variables is statistically significant, and it is a good indicator in the game of young players that the total number of blocks has increased. In 2005 the mean number of successful blocks per game was 3.81 ( $\mathrm{SD}=5.01$ ), in 2008, however, $4.75(\mathrm{SD}=5.19)$. At the same time, the mean number of blocking errors per game has also increased statistically significantly from $4.25(\mathrm{SD}=4.33)$ in 2005 to 6.85 ( $S D=5.76)$. As we can see from the proficiency index of block, the proficiency of blocking has still somewhat improved. As the difference between the indices of proficiency is not statistically significant (0.36 in 2005 and 0.44 in 2008), we can say that there exists a tendency towards improvement in blocking.

As for attacks, in the 28 championship games of 2005, 2986 attacks were performed and in the 28 games of 2008 - 3256 attacks. The total number of attacks has increased, and the total number of successful attacks also increased by 55 by 2008 (Table 4). The value of the proficiency index also increased by 2008. However, as there is no statistically significant difference between the indicators of attack, we can state, similarly to block, that there exists a tendency towards improvement of the proficiency of attack. 


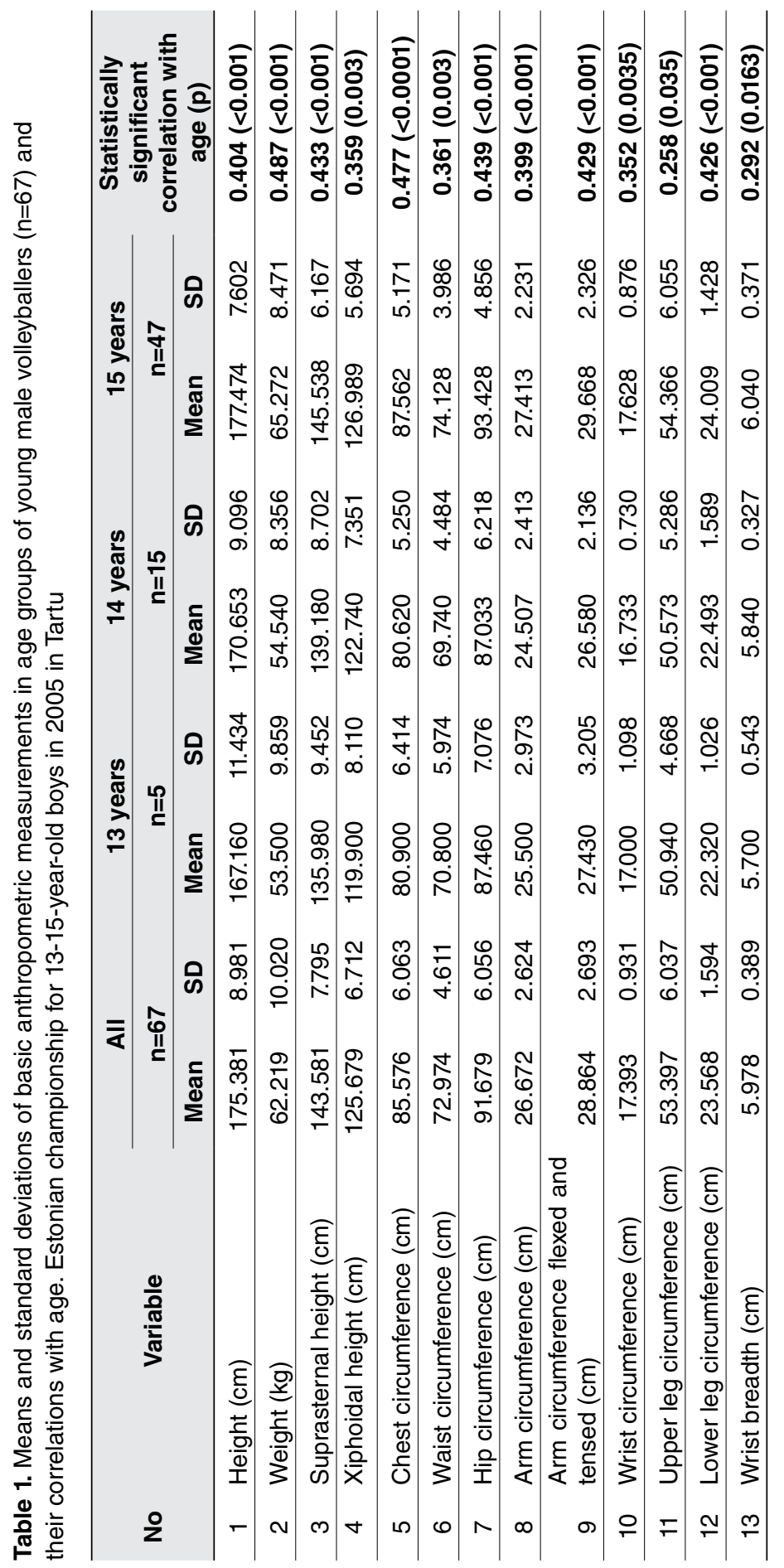




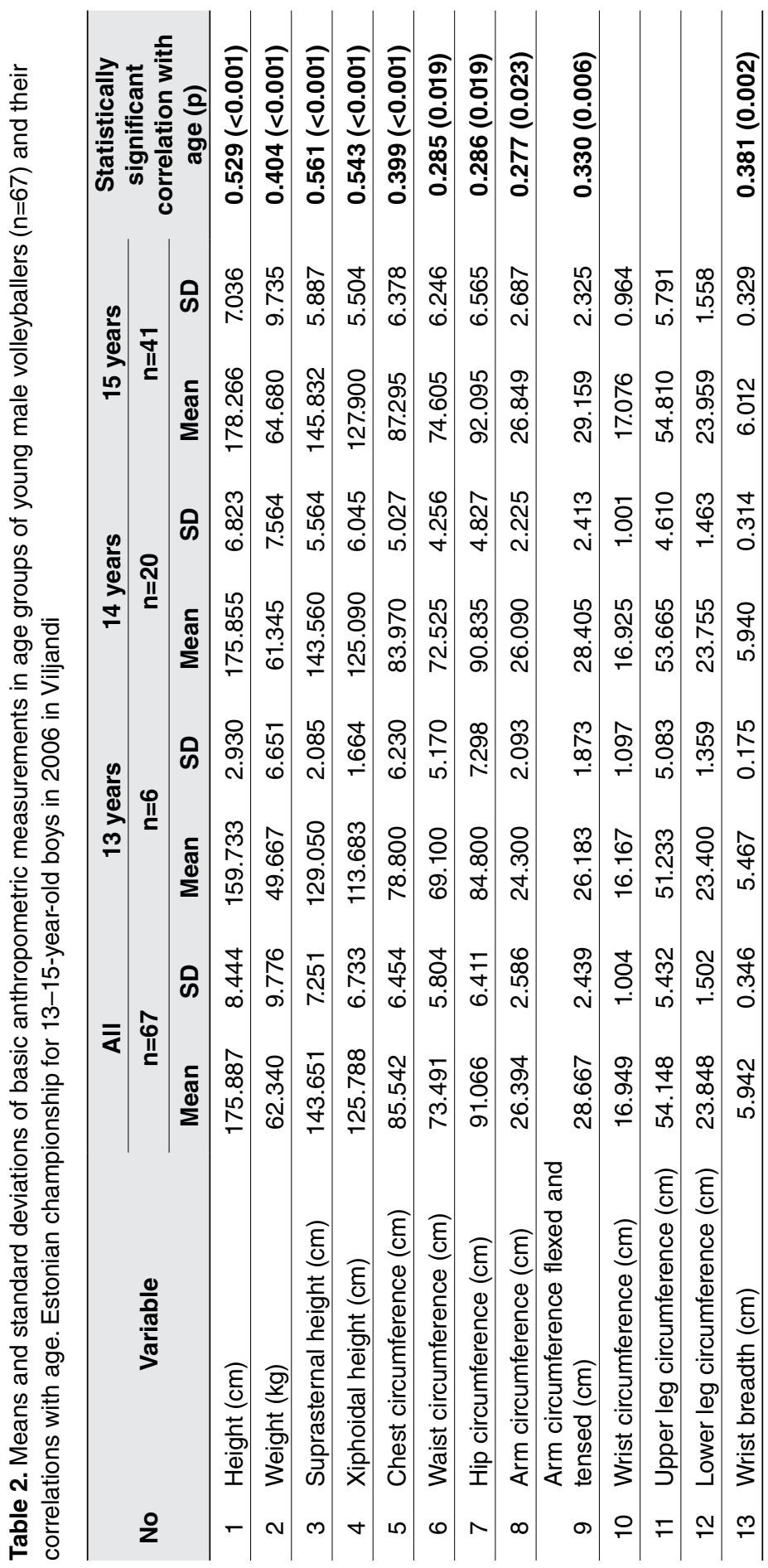




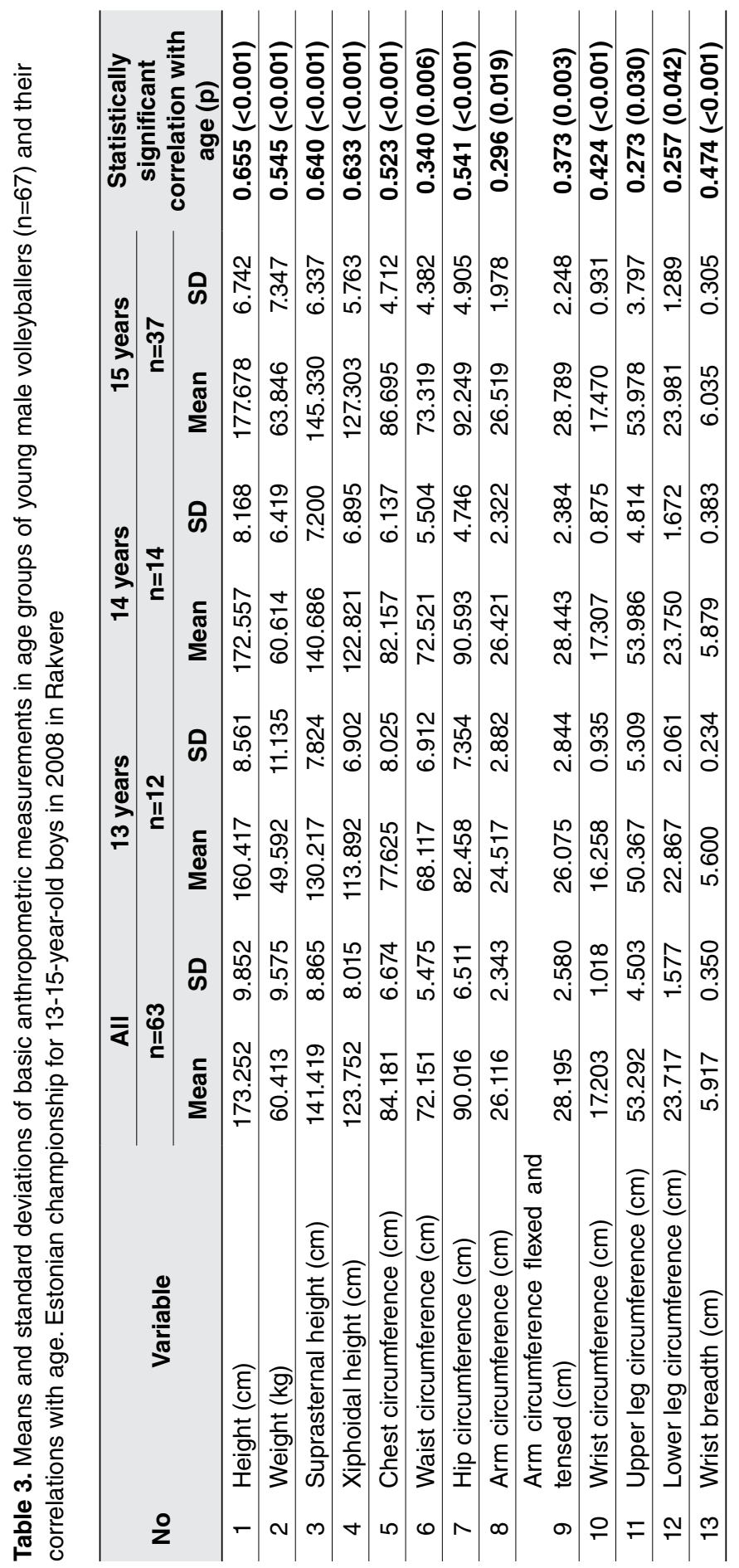




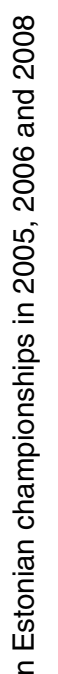

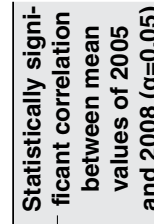

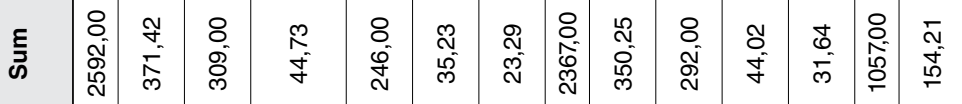

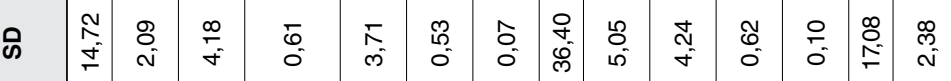

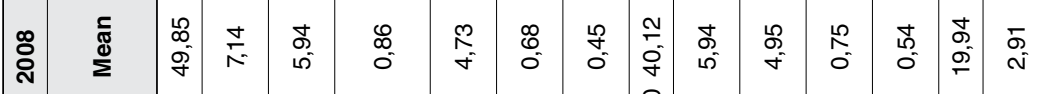

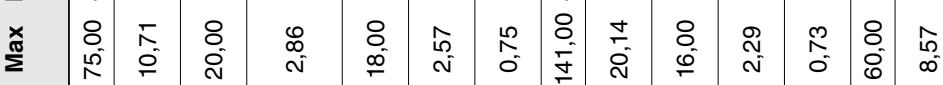

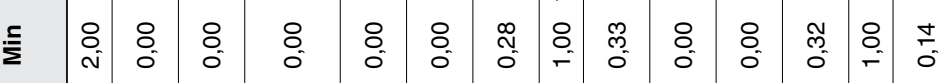

之

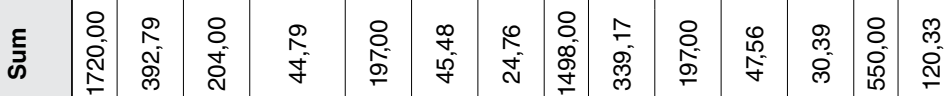

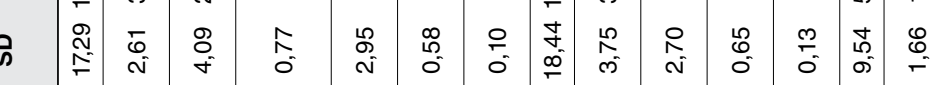

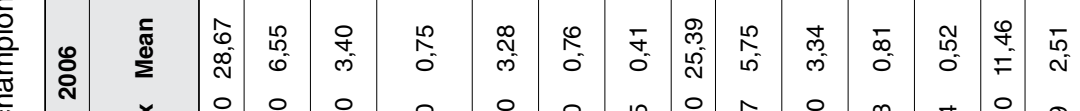

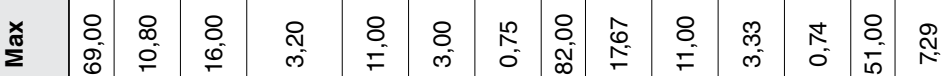

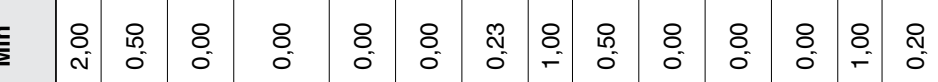

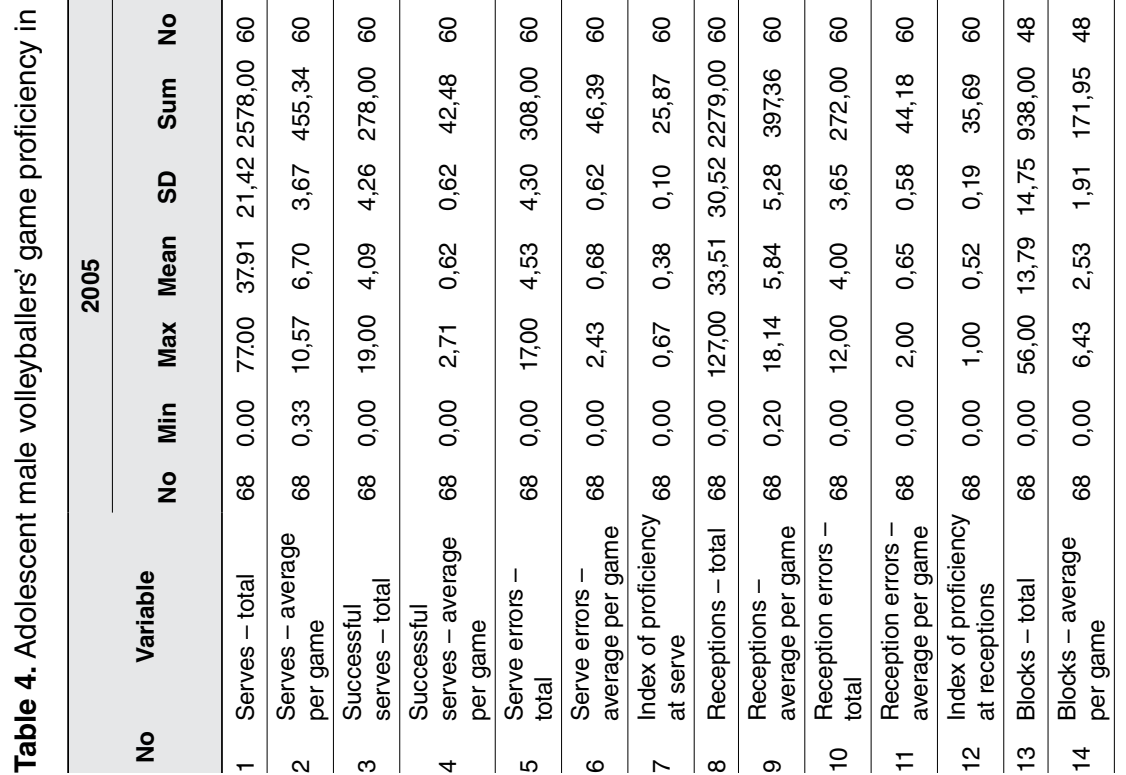



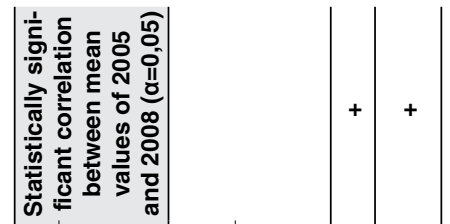

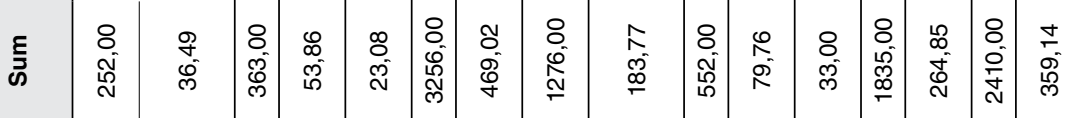

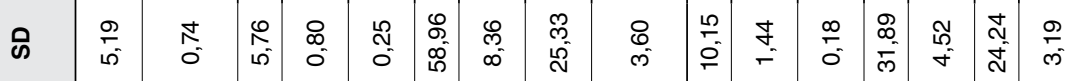

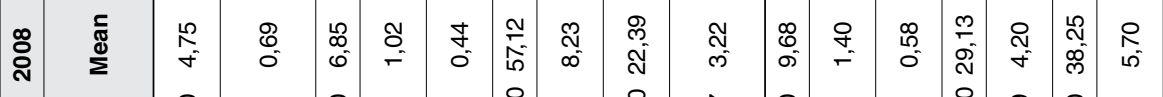

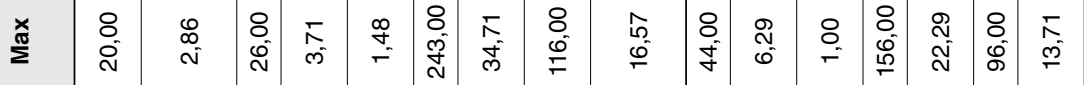

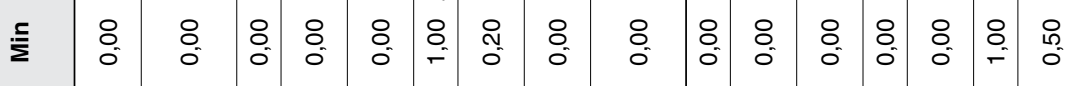

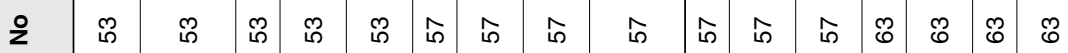

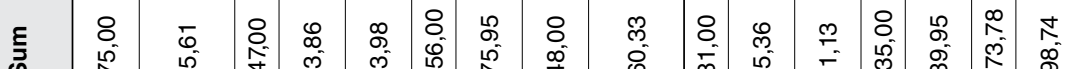

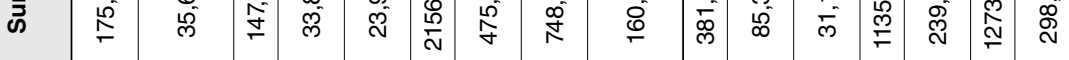

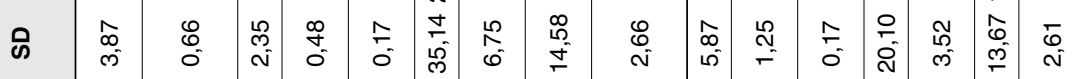

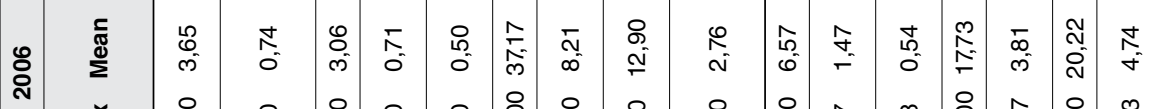

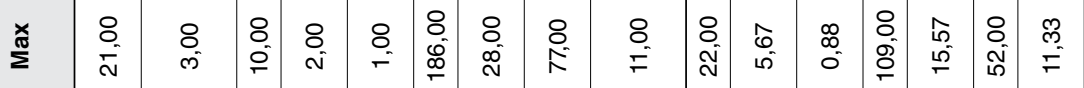

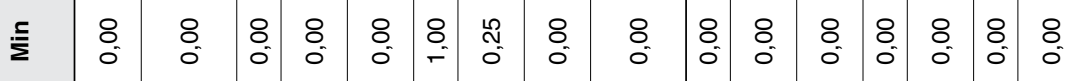

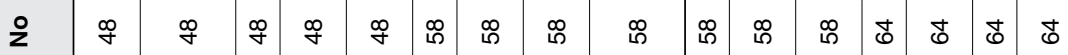

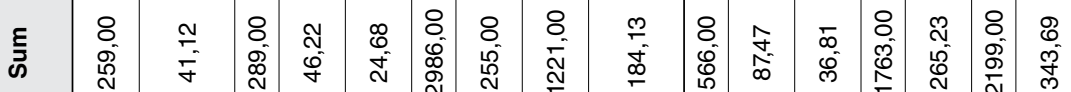

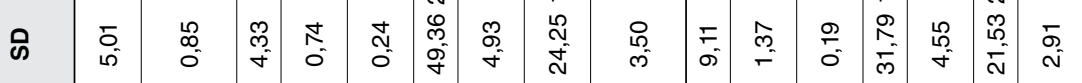

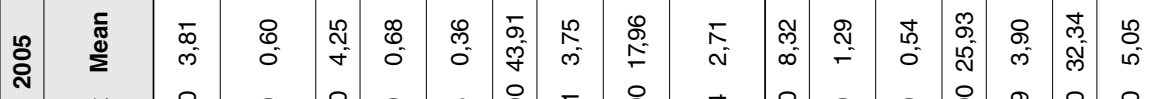

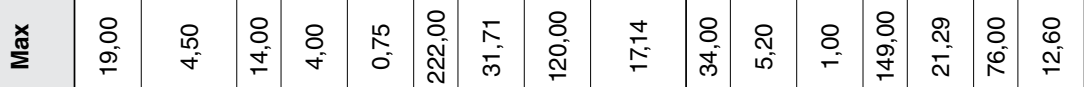
\begin{tabular}{llllllll|l|l|l|l|l|l|l|l|l|l|}
\hline & 8 & 8 & 8 & 8 & 8 & 8 & 8 & 8 & 8 & 8 & 8 & 8 & 8 & 8 & 8 & 8 \\
\hline & 0 & 0 & 0 & 0 & 0 & 0 & 0 & 0 & 0 & 0 & 0 & 0 & 0 & 0 & 0 & 0
\end{tabular} \begin{tabular}{llllllllllll|l|l|l|l|l|l|l|}
\hline $\mathbf{2}$ & $\infty$ & $\infty$ & $\infty$ & $\infty$ & $\infty$ & $\infty$ & $\infty$ & $\infty$ & $\infty$ & $\infty$ & $\infty$ & $\infty$ & $\infty$ & $\infty$ & $\infty$ & $\infty$ \\
\hline
\end{tabular}

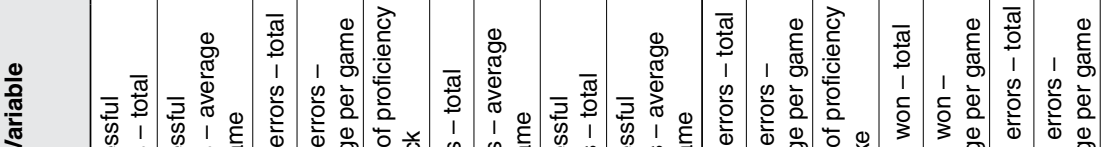

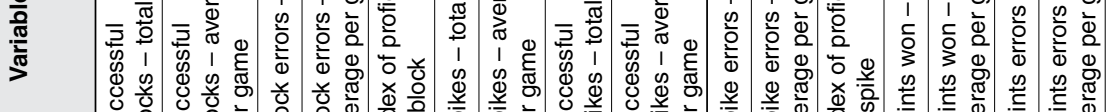

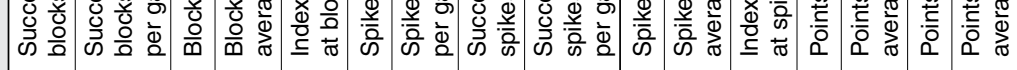

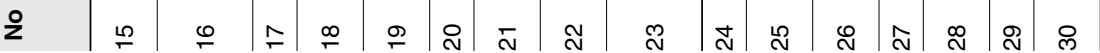




\section{DISCUSSION}

We analysed boys' basic anthropometric characteristics and their proficiency in the game during three Estonian championships for the U-16 age group in 2005,2006 and 2008. Statistical significance of differences was checked between the results of 2005 and 2008. The boys' mean body build data showed that the players of 2008 were shorter and lighter. Although there were more 13-year-olds among the players at the last tournament, the mean height and weight of boys aged 14 and 15 years had also decreased as compared to the boys of the same age in 2006. This, unfortunately, is a cause for concern, as taller players are more successful in volleyball. Literature includes many references to that $[1,2,3,5$, 9]. Unfortunately, the Estonian coaches have not been able to find taller and more promising young players for their teams in this age group.

The play of young players had also become more equal by 2008 , as the total number of blocks and attacks had increased, that of blocks - statistically significantly. The quality of games had also improved during the four years. The proficiency of serve increased statistically significantly. Serve had become a really attacking element in the games of young boys. The values of all the other indices of proficiency also increased from the first to the last tournament, but the difference was not big enough to be statistically significant. Thus, we can state that our data revealed a tendency towards improvement of block, spike and reception of serve.

\section{REFERENCES}

1. Duncan, M. J., Woodfield, L., al-Nakeeb, Y. (2006). Anthropometric and physiological characteristics of junior elite volleyball players. Br J Sport Med, 40, 649-651.

2. Dourado, A. C., Rocha, M. A., Stanganelli, L. C. R., Silvo, K. G. P., Oncken, P. (2002). Anthropometric characteristics of top level youth volleyball athletes. 7th Annual Congress Athens 24-28 VII, 2002, vol 2, 1116.

3. Fattahi, A., Ameli, M., Sadeghi, H., Mahmoodi, B. (2012). Relationship between anthropometric parameters with vertical jump in male elite volleyball players due to game's position. Journal of Human Sport and Exercise, 7 (3), 714-726.

4. Knussmann R. (1988) Anthropologie. Handbuch der vergleichenden Biologie des Menschen. Band I: Wesen und Methoden der Anthropologie. Stuttgart, New York: Gustav Fischer, 139-309.

5. Malousaris, G. G., Bergeles, N. K., Barzouka, K. G., Bayios, L. A, Nassis, G. P., Koskoloub, M. D. (2008). Somatotype, size and body composition of competitive female volleyball players. Journal of Science and Medicine in Sport, 11, 337-344. 
6. Stamm R., Stamm M., Oja A. (2000). A system of recording volleyball games and their analysis. Int J Volleyball Res, 2 (1), 18-22.

7. Stamm R., Stamm M., Koskel S. (2006). Adolescent female volleyballers' (aged 13-15 years) body build classification and proficiency in competitions. Anthropol Anz 64, 4, 423-433.

8. Stamm R., Veldre G., Stamm M., Thomson K., Kaarma H., Loko J., Koskel S. (2003). Dependence of young volleyballers performance on their body build, physical abilities and psycho-physiological properties. Br J Sport Med, 43, 1-9.

9. Zadražnik, M. (1997). Evaluation of potential success of young volleyball players. Proceedings III International Symposium, Sport of the Young. Bled, Slovenia, 7.-14.10.1997, 626-631.

\section{Adress for correspondence}

Meelis Stamm

Faculty of Educational Sciences,

Tallinn University, Tallinn, Estonia

E-mail: mella@tlu.ee 